\title{
When contrasting polarity, the Dutch use particles, Germans intonation
}

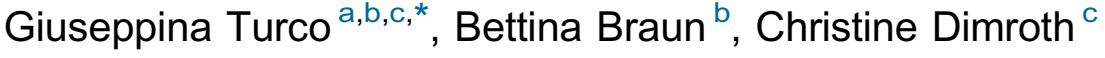 \\ ${ }^{a}$ Max Planck Institute for Psycholinguistics, Nijmegen, The Netherlands \\ ${ }^{\mathrm{b}}$ University of Konstanz, Germany \\ ${ }^{\mathrm{c}}$ University of Osnabrück, Germany
}

Received 22 April 2013; received in revised form 24 September 2013; accepted 26 September 2013

Available online 28 October 2013

\begin{abstract}
This study compares how Dutch and German, two closely related languages, signal a shift from a negative to a positive polarity in two contexts, when contrasting the polarity relative to a different topic situation (In my picture the man washes the car following after In my picture the man does not wash the car, henceforth polarity contrast) and when correcting the polarity of a proposition (The man washes the car following after The man does not wash the car, henceforth polarity correction). Production data show that in both contexts German speakers produced Verum focus (i.e., a high-falling pitch accent on the finite verb), while Dutch speakers mostly used the accented affirmative particle wel. This shows that even lexically and syntactically close languages behave differently when it comes to signalling certain pragmatic functions. Furthermore, we found that in polarity correction contexts, both affirmative particles and Verum focus were realized with stronger prosodic prominence. This difference was found in both languages and might be due to a secondary (syntagmatic) effect of the information structure of the utterance (absence or presence of a contrastive topic).
\end{abstract}

(c) 2013 Elsevier B.V. All rights reserved.

Keywords: Verum focus; Particles; Intonation; Information structure; Polarity contrast; Polarity correction

\section{Introduction}

Natural languages offer a variety of linguistic means to encode the semantic and pragmatic contribution of utterances. In this paper we investigate the use of intonation and particles to contrast an utterance's polarity; our study is crosslinguistic and compares two closely related West Germanic languages, Dutch and German. More specifically, we analyze utterances that assert a claim that was previously denied, as in the B-utterances in the German examples (1) and (2) (accents are marked by capitals).

(1) Polarity contrast

A: Auf meinem Bild hat das Kind nicht geweint. ("In my picture the child did not cry")

B1: Auf meinem Bild HAT das Kind geweint. ("In my picture the child DID cry")

B2: Auf meinem Bild hat das Kind SCHON/WOHL geweint. ("In my picture the child did INDEED cry")

\footnotetext{
* Corresponding author at: University of Konstanz FB SprachWissenschaft P.O. Box 186 - 78457 Konstanz (Germany). Tel.: +49 0753188 4265; fax: +4907531884149.

E-mail addresses: giuseppina.turco@uni-konstanz.de, giusy.turco@mpi.nl (G. Turco), bettina.braun@uni-konstanz.de (B. Braun), christine.dimroth@uni-osnabrueck.de (C. Dimroth).
} 
(2) Polarity correction

A: Das Kind hat nicht geweint. ("The child did not cry")

B1: Das Kind HAT geweint. ("The child DID cry")

B2: Das Kind hat SCHON/WOHL geweint. ("The child did INDEED cry")

In example (1), speakers A and B assert that similar descriptive properties (i.e., a child having cried) apply or do not apply with respect to different picture-situations (in Klein's (2008) terms 'topic situation', see also Horn (1985)). If the topic is new or contrastive, the claims with negative and positive polarity do not exclude each other (henceforth 'contrast', see Umbach, 2004). On the other hand, the two speakers talk about the same situation in example (2). Here, the topic is maintained and speakers are making negative and affirmative claims about the same topic situation (e.g., the same picture); that is the claims are mutually exclusive (henceforth 'correction', see, Umbach, 2004). ${ }^{1}$

The cross-linguistic comparison of German and Dutch polarity contrast marking is interesting as both languages are considered 'assertion-oriented' (Dimroth et al., 2010): Speakers of such languages tend to overtly mark the contrast between negative and affirmative assertions, whereas speakers of Romance languages, for instance, usually highlight the contrast between other information structure units (e.g., the topics) in the same contexts.

Despite the similarity between German and Dutch assertion marking, there appear to be differences in their linguistic realization. Speakers of German have been argued to use Verum focus in these contexts, that is an accent on the finite verb (e.g., Höhle, 1988, 1992). More specifically, Höhle argues that the verb is associated with a VERUM operator, which becomes prominent when the verb is accented (Höhle, 1992: 114). In the B1-utterances of examples (1) and (2) Verum focus is marked by a pitch accent on the finite auxiliary (indicated by capitals). The term Verum focus is motivated by the proposal that it is the truth of the proposition that is in focus (Höhle, 1988, 1992). ${ }^{2}$ Other accounts (Klein, 1998, 2006; Lohnstein, 2012), on the other hand, assume that the accent on the finite verb highlights the assertive relation between the topic and the comment of the utterance. Finiteness expresses assertion and tense. Therefore, the accent on the finite verb can induce, among others, an assertion contrast (Klein, 1998), or lead to a "focus of affirmation" (Bolinger, 1983); in this paper we concentrate on this particular function of accented finite verbs.

In addition to intonation, Dutch and German are equipped with affirmative particles ${ }^{3}$ (e.g., Dutch: toch, wel; German: doch, wohl, schon) whose precise meaning contributions are still under discussion (e.g., Foolen, 2006; Hogeweg et al., 2011). Notably, some of these particles can take the same function as Verum focus; the affirmative function of these particles in contrastive and corrective contexts is linked to the accented version only (see Hogeweg, 2009; Sudhoff, 2012 for recent analyses along these lines). Apparently, the use of such affirmative particles is more widely acknowledged for Dutch than for German. For the Dutch particle wel, Sudhoff (2012: 105) even assumes that "focus on this particle is in fact an instance of Verum focus". However, to date there is only very little comparative experimental evidence to lend direct support to these language-specific preferences in marking polarity contrast and correction, a gap which this paper aims to fill.

Before we turn to the empirical studies, we revise previous studies on polarity marking in both languages.

\section{Background}

\subsection{Affirmative particles}

In this section we focus on the Dutch affirmative particle wel. Recent contributions by Hogeweg (2009) and Sudhoff (2012) suggest that the stressed variant of the Dutch affirmative particle wel should be considered as positive counterpart of the negation niet and is hence similar to Verum focus. Hogeweg (2009) investigates a corpus containing wel in corrective, contrastive and a variety of other contexts and shows that there is always an explicit or implicit negation in the preceding context. The author comes to the conclusion that "the stronger the negation in the context, the stronger wel has to be to 'undo' that negation" (2009: 535, single quotes added). The idea of prominence as an indicator of the extent of "undoing" a context negation is appealing for corrective contexts. However, it is difficult to extend the claim to contrastive contexts, in which it is not the function of the particle to "undo" the negation, but rather to signal the contrastive relation between the affirmative statement and the preceding negative one. The different functions of the affirmative particle

\footnotetext{
${ }^{1}$ See also Dik et al.'s (1981) notion of 'expanding' for contrast and 'replacing' for correction.

2 Different approaches concerning the semantic properties and the syntactic implementation of a verUm operator as well as its relation to other types of foci are under discussion (see, for instance, all contributions in Lohnstein and Blühdorn, 2012; Repp, 2013).

${ }^{3}$ See also the terms polarity particles (Sudhoff, 2012), assertion-related particles (Klein, 2012) or Westheide's (1985) Konversationskonnektiv mit Widerspruchscharakter ("discourse connective with contradictory character").
} 
become evident when one considers monologues instead of dialogues. Example (3) is an utterance produced by a native speaker of Dutch in a film-retelling task (Dimroth et al., 2010):

[context setting: There is a house on fire]

(3) Meneer Rood durft niet te springen. Meneer Blauw is WEL gesprongen want het vuur stond inmiddels ook al in zijn kamer.

("Mr Red does not dare to jump. Mr Blue is indeed jumping because there is already fire in his room"). (example taken from the 'Finite Story' data, see Dimroth et al., 2010)

As in example (1) above, the speaker in (3) is not contradicting or negating an earlier claim. Rather, both claims are compatible with one another, as long as the speaker talks about two different topic situations (here: two topic entities, Mister Red and Mister Blue). The contrast between the utterances (i.e., Mister Red is not jumping, Mister Blue is jumping) could therefore be left unmarked, and in narrative contexts like the one in (3), this is indeed the case in roughly half of the cases (Dimroth et al., 2010). Other speakers draw attention to the potential contrast by using particles or intonation, without, however, "undoing" earlier claims.

In German, affirmative particles appear to be used less frequently than in Dutch. This was shown for polarity contrast contexts in a film-retelling situation (Dimroth et al., 2010). Here we investigate whether this cross-linguistic difference in the use of affirmative particles for polarity marking also holds in more interactive situations (dialogues as compared to monologues) and in the context of corrections.

\subsection{Verum focus}

It is well-established that in German or Dutch neutral declarative sentences, the sentence accent (i.e., the nuclear pitch accent) falls on the internal argument (e.g., Féry and Samek-Lodovici, 2006; Gussenhoven, 1992; Truckenbrodt, 2012; Uhmann, 1991). In cases of contrastive focus, stress-assignment rules and information structure principles interact in such a way that focus attracts the strongest accent and post-focal background information rejects any accent and is therefore deaccented. Hence, if Verum focus is a case of contrastive focus (cf. Klein, 2006; Lohnstein, 2012), the pragmatic focus on the finite verb attracts the nuclear pitch accent, whereas the rest of the (contextually given) sentence is deaccented. In recent semi-spontaneous productions of contrastive Verum focus in German, Turco et al. (2012) showed that this was indeed the case in German. German speakers marked polarity contrast by producing a high-falling nuclear pitch accent on the finite verb and post-focal deaccentuation (i.e., Verum focus).

In Dutch, it seems that locating the nuclear pitch accent on the finite verb evokes other pragmatic meanings than in German (Gussenhoven, 1983, 1999). Dutch utterances with a nuclear pitch accent on the finite verb and no particle are claimed to be 'counter-presuppositional' ${ }^{4}$ (e.g., speaker A: He READS books in reply to speaker B: If he read books, he would know this, taken from Gussenhoven, 1999: 52). If an utterance contains the accented particle wel (and there is no accent on the finite verb), a polarity contrast or correction are expressed (e.g., speaker A: He DOES read books in reply to speaker B: He doesn't read books, taken from Gussenhoven, 1999: 52).

\subsection{Hypotheses}

On the basis of the studies revised above, we expect that Dutch and German differ in the linguistic means used to mark a switch from a negative to a positive polarity. Furthermore, considering that a correction is 'replacing' information in the interlocutor's discourse representation (while a contrast is merely adding/'extending' information), we also expect that the linguistic means used in each language are realized with greater prosodic prominence in a corrective compared to a contrastive context.

\section{Experiments}

In this study we will use the same experimental procedure as in Turco et al. (2012), with speakers of Dutch and German. We will compare the linguistic means to mark polarity contrast (different topic situations) and polarity correction (same topic situation) in Dutch and German.

\footnotetext{
${ }^{4}$ Watters (1979) calls this reading 'counter-assertive'. Given the distinction between the assertion level and the polarity level introduced before, we refrain from using this term.

${ }^{5}$ For examples in Dutch, see Gussenhoven (1983).
} 


\subsection{Methods}

We used two task procedures to elicit a 'polarity-switch' from negation to affirmation: a 'picture-difference' task and a 'picture-matching' task.

In the picture-difference task, a mini-dialogue between a confederate speaker and the participant results from a comparison of three pictures: (a) a 'baseline' picture, accessible to both speakers, in which a situation is illustrated (e.g., a man washing a car); (b) a 'negation' picture, in which the opposite event is depicted (e.g., the man is not washing the car), only accessible to the confederate; (c) an 'affirmation' picture that is identical to the baseline picture (e.g., the man is washing the car), only accessible to the participant. The role of the baseline picture is to contextualize the use of a negative description by the confederate (e.g., confederate speaker: In my picture the man is not washing the car - participant: In my picture the man is washing the car). This procedure allowed us to elicit polarity contrast mini-dialogues where the context negation utterance (provided by the confederate) and the affirmative utterance (spoken by the participant) relate to different topic situations (i.e., two different pictures).

The picture-matching task contains auditory event descriptions that match or mismatch events illustrated on pictures. The mismatching condition allowed us to elicit cases of polarity correction: the context negation utterance (provided by the audio stimulus) and the affirmative utterance (spoken by the participant) are referring to the same topic situation such that the utterances are mutually exclusive. In the matching condition, participants are not supposed to react verbally but just had to press the enter button for passing onto the next picture.

\subsubsection{Participants}

The German group comprised of 14 monolingual speakers ( 3 male and 11 female, average age $=23.7, S D=2.3$ ), who were students at the University of Heidelberg (Germany). They originated from different parts of Germany but all spoke Standard German. For the Dutch group, 14 monolingual speakers ( 2 male and 12 female, average age $=21.6, S D=2.1$ ) were recorded. They were all students at the Radboud University Nijmegen (The Netherlands) and they all spoke Standard Dutch. None of the participants had a reported history of speech/language impairment or other developmental deficits. All participants received a small fee for their participation.

\subsubsection{Materials}

In the picture-difference task, there were 32 polarity-switch trials (i.e., focus on the polarity with an additional contrastive topic, e.g., In my picture the man is washing the car), 32 non-polarity switch trials (i.e., focus on the whole predicate), and 50 filler trials (i.e., focus on other constituents of the utterance). Of the 32 polarity-switch trials, 12 had an auxiliary followed by a non-finite verb (e.g., Dutch: heeft gewassen, German: hat gewaschen, "has washed"), 12 a finite lexical verb (e.g., Dutch: wast, German: wäscht, "washes") and 8 a copula construction e.g., Dutch: is, German: ist, "is").

The picture-matching task included 32 polarity-switch trials (i.e., focus on the polarity with no contrastive topic, e.g., the man is washing the car) and 64 filler trials (32 with a mismatching verb and 32 matching trials). Of the 32 polarity-switch trials, 12 were auxiliary verbs, 12 lexical verbs and 8 copula verbs. In these polarity-switch trials, the respective picture is presented together with a negated description of the event and participants hence corrected the proposition (same topic situation). Fig. 1 shows an example item of the picture-matching task in Dutch.

The picture-matching task included prerecorded audio stimuli. These were recorded in a sound-booth cabin by a German native speaker (thirty years old) and by a Dutch native speaker (twenty-four years old), respectively. All the audiorecorded context utterances contained a pitch-accented negation particle (i.e., NICHT for German, NIET for Dutch). The filler trials were all recorded with a neutral declarative intonation.

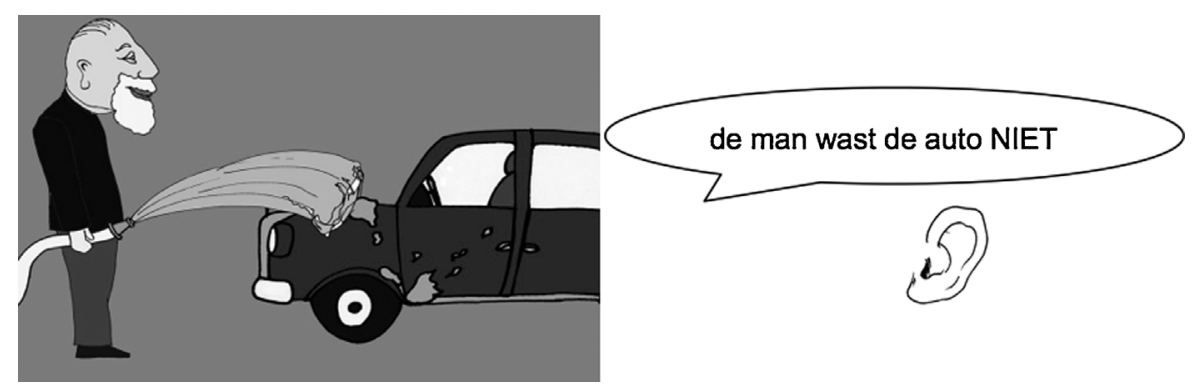

Fig. 1. Example of picture-matching task trial with mismatching visual and auditory information. 
The pictures used in the two tasks were slightly different to keep participants engaged. However, the types of actions illustrated in the pictures were similar across tasks (e.g., washing a shirt in the polarity contrast task, washing a car in the polarity correction task).

\subsubsection{Procedure}

In the picture-difference task, the baseline pictures were displayed on an IBM screen, the individual pictures on two e-book readers, one for the confederate and one for the participant. Each picture described a single event. In the polarityswitch condition, the confederate described the negation picture in comparison to the baseline picture. For each language, there was one native language confederate speaker: a female speaker of Standard German (twenty-six years old) for the German group and a male speaker of Standard Dutch (twenty-three years old) for the Dutch group. They were instructed to keep eye-contact and were trained beforehand on the intonation contours to use such that they could produce the same intonation pattern for all participants and all items. In particular, for the polarity-switch condition, the confederate produced an accent on the negation. The confederate had the first turn in all the mini-dialogue trials. The interlocutors could not see each other's pictures and were not pressured by any time constraints. In order to encourage participants to produce full sentences, they were told that their productions would later be used for another experiment, in which somebody else would have to match the corresponding pictures to their descriptions.

In the picture-matching task, participants were seated in front of an e-book reader where only one picture was displayed and accompanied by an audio stimulus, played directly from the e-book. Participants first saw the picture (e.g., a man washing a car). After $2000 \mathrm{~ms}$, they heard a sentence uttering a proposition that matched or did not match the pictured event. Participants had to correct anytime they encountered a mismatch trial. The visual and the verbal stimuli were presented using the Presentation software (version 14.9, http://www.neurobs.com/).

All sessions took place in quiet experiment rooms: the German group was recorded at the University of Heidelberg in Germany, the Dutch group was recorded at the Max Planck Institute for Psycholinguistics in Nijmegen. Sessions were sound-recorded using a Roland Edirol R-09 24bit digital wave/MP3 recorder and a Sennheiser ME40 phantom microphone placed at approximately $30 \mathrm{~cm}$ distance from the participant.

All participants first took part in the picture-difference task and then in the picture-matching task. They were engaged in the accomplishment of other unrelated tasks in-between (e.g., film-retelling, filling in a background questionnaire). The whole experimental session lasted on average $45 \mathrm{~min}$.

For both tasks, two experimental lists were created with a pseudo-randomized order of the trials (separating two trials with the same condition by at least two other trials). Participants were assigned randomly to one of the two lists. At the beginning of each task, they were familiarized in a short warm-up session containing 4 trials.

\subsection{Results}

\subsubsection{Data selection}

Both datasets consisted of 448 polarity contrast utterances and 448 polarity correction utterances (i.e., 32 trials $\times 14$ speakers $=448$ ). In the Dutch dataset, we had to discard 106 utterances ( 55 utterances in the polarity contrast and 51 utterances in the polarity correction), mostly because speakers used elliptical structures, other verbs, or did not interpret the picture as intended and therefore gave unexpected responses. In the German dataset, a total of 192 utterances had to be discarded (111 utterances of the polarity contrast, 81 utterances of the polarity correction). Table 1 shows the number of polarity contrast and polarity correction utterances left for the analyses.

We coded the utterances at the word and syllable level. The intonational analysis was performed using GToBI (German Tone and Break Indices) for German (Grice et al., 2005) and ToDI (Transcription of Dutch Intonation) for Dutch (Gussenhoven, 2005). All statistical analyses were conducted with the R software package (2012).

In what follows we will present the analyses of the linguistic means (i.e., affirmative particles and/or Verum focus) used in each language and compare the degrees of prominence across context conditions (i.e., polarity contrast and correction). Due to the presence of two context conditions and of different types of linguistic markings, we found it clearer to first present the results for each language separately and then perform statistic analyses on possible cross-linguistic effects on the linguistic means produced in both contexts. Furthermore, verb type (i.e., lexical verbs, auxiliary verbs,

Table 1

Number of utterances analyzed in the two contexts and for each language.

\begin{tabular}{lll}
\hline Context & Dutch & German \\
\hline Polarity contrast & 393 & 337 \\
Polarity correction & 397 & 367 \\
\hline
\end{tabular}




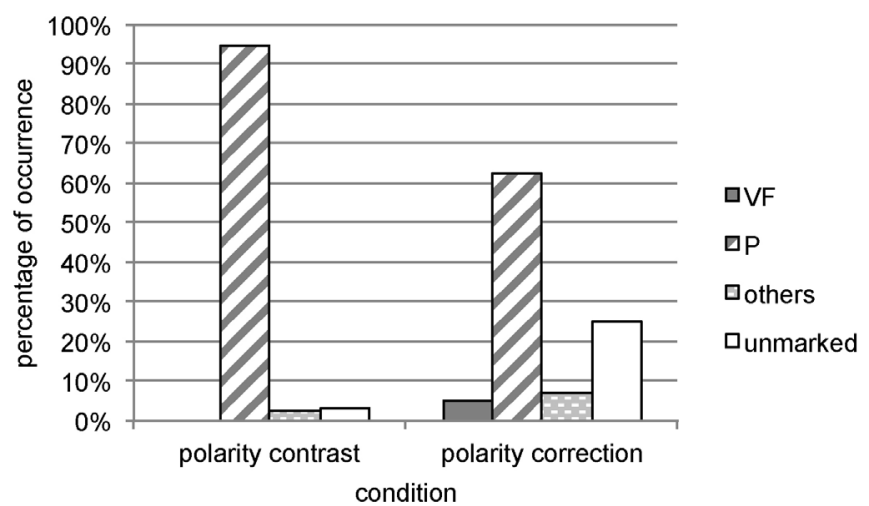

Fig. 2. Averaged distribution in \% of Verum focus (VF), affirmative particles (P), other realizations (others) and unmarked cases produced in polarity contrast and in polarity correction by Dutch speakers.

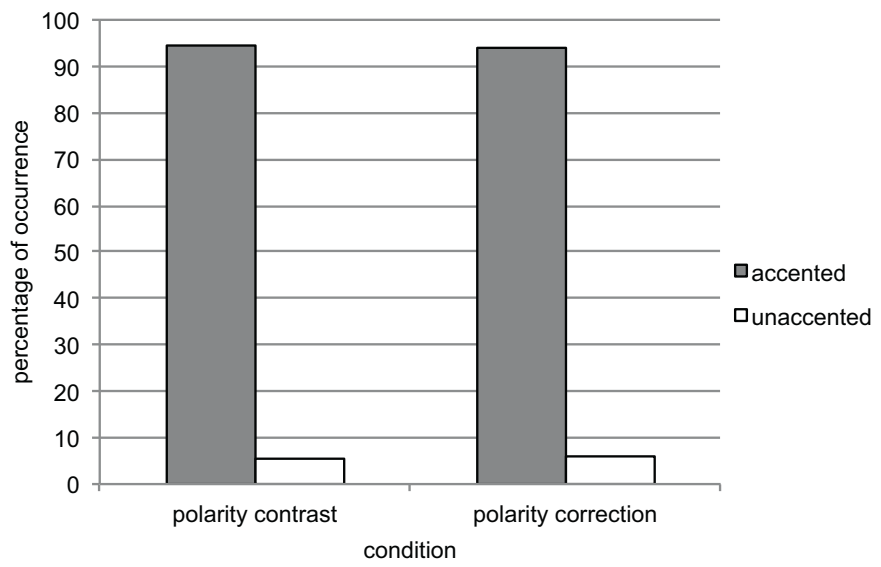

Fig. 3. Averaged distribution in $\%$ of accented vs. unaccented wel produced in polarity contrast and in polarity correction by Dutch speakers.

copula verbs, cf. 3.1.2) did not have a main effect and no interaction with other factors (i.e., condition and language) and will hence not be considered further.

\subsubsection{Dutch}

We analyzed the use of Verum focus, affirmative particles, no marking (i.e., cases without particles and with a nuclear pitch accent on the object noun, the default position) and other realizations (e.g., an accent on the non-finite verb in the auxiliary condition or an additional, prenuclear accent on the finite verb in the copula and in the lexical conditions, preceding the nuclear accent on the object noun). Two speakers were excluded from this analysis as they did not mark the polarity correction at all, in none of the 32 trials, and hence did not appear to take the task seriously anymore. The distribution of linguistic means across contexts for 12 of the 14 speakers is illustrated in Fig. 2.

Fig. 2 shows that in polarity contrast Dutch speakers realized Verum focus in none of the cases and in polarity correction in only $5.4 \%$ of the cases. Instead, they used the affirmative particle wel far more often than the other linguistic means. ${ }^{6}$ Surprisingly, there was a high proportion of unmarked cases in the polarity correction condition. To corroborate the observed differences, we ran a multinomial logistic regression analysis (Bates and Sarkar, 2007; Jaeger, 2008) with LINGUISTIC MEANS (the ones illustrated in Fig. 2; the reference category was set to the category 'unmarked') as a function of CONDITION (polarity contrast, polarity correction). The analysis revealed that overall, there were significantly more affirmative particles $(\beta=3.47, \mathrm{SE}=0.32, \mathrm{p}<.0001)$ and significantly less Verum focus productions $(\beta=-2.30$, $\mathrm{SE}=1.04, \mathrm{p}<.05) .^{7}$ Furthermore, compared to the polarity contrast condition, there were significantly less affirmative

\footnotetext{
${ }^{6}$ Note that particles were only produced in polarity contrasts/corrections and never in the filler trials without a polarity-switch.

7 Since a multinomial logistic regression analysis cannot be calculated if there are no instances in a given condition, we changed one instance of affirmative particle to a Verum focus in polarity contrast contexts (for a similar procedure see, Braun and Chen, 2010; Turco et al., 2012).
} 
particles $(\beta=-2.42, \mathrm{SE}=0.34, \mathrm{p}<.0001)$ in the polarity correction, whereas there was no effect of condition on the frequency of Verum focus (all p-values $>.4$ ) and a marginal effect on the frequency of 'others' $(\beta=-0.96, \mathrm{SE}=0.52$, $p=.06)$. Finally, the effect of condition approached significance for the category 'unmarked' as well $(\beta=0.96, S E=0.52$, $p=.06)$.

According to the literature, the affirmative particle is usually accented (e.g., Hogeweg, 2009; Sudhoff, 2012). We performed an acoustic analysis to corroborate this prediction. A production of wel was classified as accented if it sounded prominent and was accompanied by a prominence-lending f0-movement; unaccented wel were not pitch-accented. Twenty-five cases of sentence-final wel, which were realized with audible creaky voice were excluded (19 occurrences in polarity contrast and 6 in polarity correction, accounting for $4.8 \%$ of the data), because the creaky voice made it impossible to reliably determine whether they were accented or not. Fig. 3 shows the average percentages of accented vs. unaccented wel in the two contexts.

Fig. 3 demonstrates that the particle wel was indeed mostly accented. A binomial logistic regression analysis (Baayen, 2008; Pinheiro and Bates, 2000) with ACCENTUATION OFWEL (Yes, No) as a function of CONDITION (polarity contrast, polarity correction), with SPEAKER and ITEM as cross-random factors, confirmed that accented particles were significantly more

a
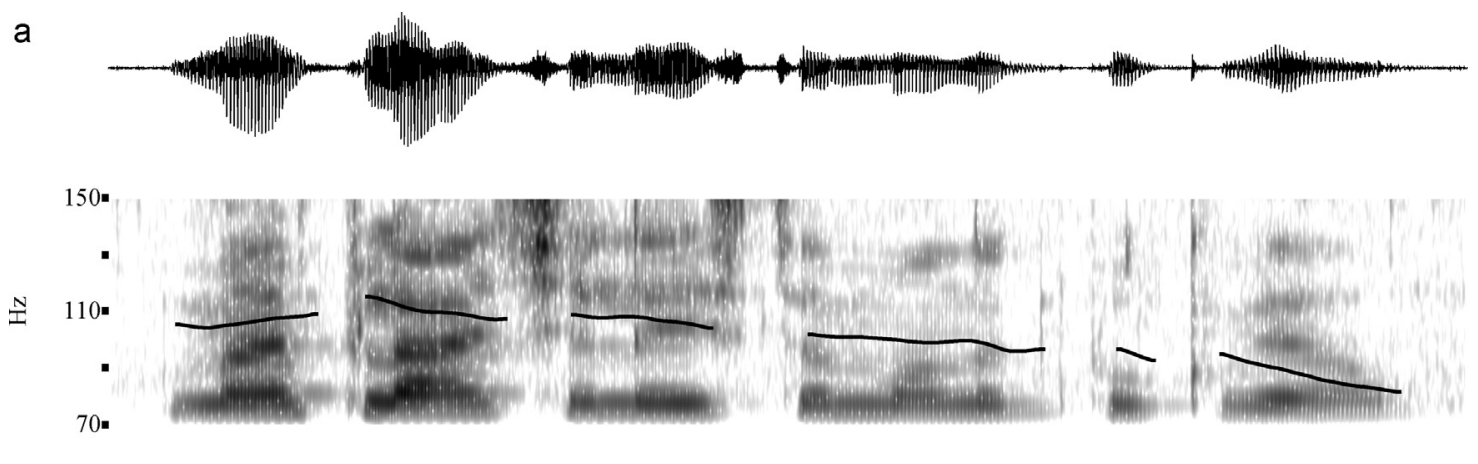

\begin{tabular}{|c|c|c|c|c|}
\hline Op mijn plaatje & leest & de man & het boek & wel \\
\hline In my picture & reads & the man & the book & PRT \\
\hline \multicolumn{5}{|c|}{ In my picture the man is indeed reading the book } \\
\hline$\% \mathrm{~L}-\mathrm{H}^{*}$ & & & & ${ }^{\prime} L-L \%$ \\
\hline
\end{tabular}

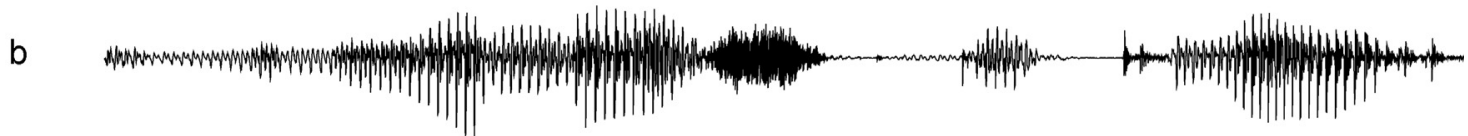
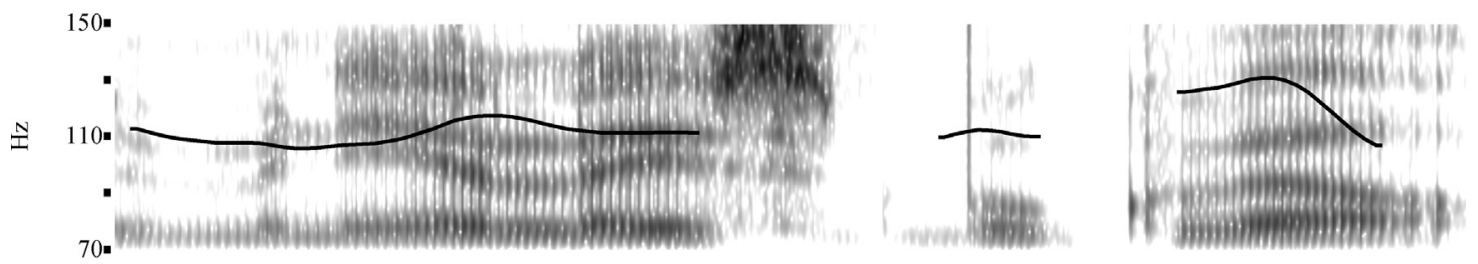

\begin{tabular}{|c|c|c|c}
\hline De meneer & leest & de boek & wel \\
\hline The man & reads & the book & PRT \\
\hline \multicolumn{4}{|c}{ The man is indeed reading the book } \\
\hline \multicolumn{2}{c}{$\mathrm{L}^{*} \mathrm{H}$}
\end{tabular}

Fig. 4. ( $a$ and $b$ ) Example pitch tracks of the particle wel realized as a downstepped fall ! $H^{*} L$ in polarity contrast (top panel, female speaker) and as a fall $\mathrm{H}^{*} \mathrm{~L}$ in polarity correction (bottom panel, male speaker). The ToDI annotations are shown in the last tier. 
frequent than unaccented particles $(\beta=3.11, \mathrm{SE}=0.29, \mathrm{p}<.0001)$. There was no effect of condition on the accentuation of wel $(p=.58)$.

Finally, we analyzed the intonational realization of the particle wel across tasks to find support for Hogeweg's generalization (cf. section 2.1) about different degrees of prominence of wel in relation to the type of context. We found two general contours, one in which there was a rise on the contrastive topic "In my picture" followed by a downstepped fall on the particle wel (i.e., ! $\mathrm{H}^{*} \mathrm{~L} \mathrm{~L} \%$, following ToDI conventions, Gussenhoven, 2005), as shown in Fig. 4(a), and one in which there was a fall on the particle wel, with or without further accents on nominal elements before it $\left(\mathrm{H}^{*} \mathrm{~L} L \%\right.$, see Fig. 4(b)). The particle wel sounded more prominent when it was realized with a fall, compared to a downstepped fall.

Fig. 5 shows the distribution of accent types realized on wel: downstepped falls (i.e., ! $H^{*} L \mathrm{~L} \%$ ), falls (i.e., $H^{*} L \mathrm{~L} \%$ ) and other accentual realizations comprising cases of wel realized as a 'low rise' (i.e., $\mathrm{L}^{*} \mathrm{H} \mathrm{H} \%$ ) or as a 'high rise' (i.e., $\mathrm{H}^{*} \mathrm{H} \%$ ) following ToDI (both collapsed under the category 'others'). The particle wel was mostly realized as a downstepped fall $\left(! \mathrm{H}^{*} \mathrm{~L} \mathrm{~L} \%\right)$ in polarity contrast and mostly as a fall in polarity correction.

To corroborate the differences across conditions, we calculated a multinomial logistic regression analysis with TYPE OF ACCENT (the accents shown in Fig. 5) as a function of CONDITION (polarity contrast, polarity correction, the reference category was set to the category 'others'). The model confirmed that compared to polarity contrast, in polarity correction the particle wel was produced significantly more often as a fall $\left(\mathrm{H}^{*} \mathrm{~L}: \beta=1.76, \mathrm{SE}=0.31, \mathrm{p}<.0001\right)$ and less often as a downstepped fall $\left(! \mathrm{H}^{*} \mathrm{~L}: \beta=-1.14, \mathrm{SE}=0.25, \mathrm{p}<.0001\right)$.

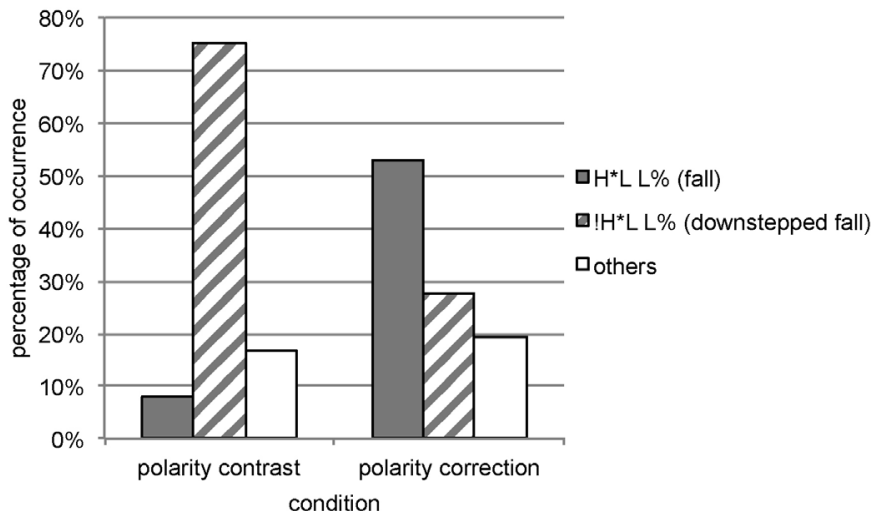

Fig. 5. Averaged distribution in \% of the accentual realizations on (the accented cases of) wel produced in polarity contrast and in polarity correction by Dutch speakers.

\subsubsection{German}

The German data were coded in the same way as the Dutch data (Verum focus, affirmative particles, others and unmarked), see Fig. 6. In German, the category 'others' did not include any instances of an accent on the non-finite verb. Instead, there were some cases, in which participants first produced the particle doch as a separate utterance, followed by an utterance with Verum focus (see example pitch track in the Appendix).

Fig. 6 shows that German speakers never realized affirmative particles, in any of the polarity contexts. Instead, they produced Verum focus in more than $70 \%$ of the cases, far more often than the other options. A multinomial logistic regression analysis with LINGUISTIC MEANS (as illustred in Fig. 6; the reference category was set to the category 'unmarked') as a function of CONDITION (polarity contrast, polarity correction) revealed that overall, there were significantly more Verum focus productions $(\beta=1.62$, SE $=0.14, \mathrm{p}<.0001)$, significantly less affirmative particles $(\beta=-4.00, \mathrm{SE}=1.00$, $\mathrm{p}<.0001)$ and other realizations $(\beta=-4.09$, SE $=1.10, \mathrm{p}<.0001)$. Furthermore, there was an effect of condition: the category 'others' (i.e., Doch + Verum focus) was more frequent in polarity correction than in polarity contrast $(\beta=3.96$, $\mathrm{SE}=1.03, p<.0001)$, whereas no such effect was found on the frequency of Verum focus and affirmative particles (all p-values >.2). Fig. 7(a) and (b) show typical examples of Verum focus on the finite auxiliary (hat, "has") realized in polarity contrast and in polarity correction.

In order to corroborate the effect of language on the types of linguistic means (Verum focus and/or affirmative particles), we ran a binomial logistic regression model with LINGUISTIC MEANS (Verum focus, affirmative particles shown in Figs. 2 and 6) as a function of LANGUAGE (Dutch vs. German) and CONDITION (polarity contrast, polarity correction). SPEAKER and ITEM were added as cross-random factors. ${ }^{8}$ In both contexts, there was a highly significant effect of LANGUAGE

\footnotetext{
${ }^{8}$ For the reasons explained in footnote 7 , we changed one instance of Verum focus to a particle in both German contexts (for a similar procedure see, Braun and Chen, 2010; Turco et al., 2012).
} 


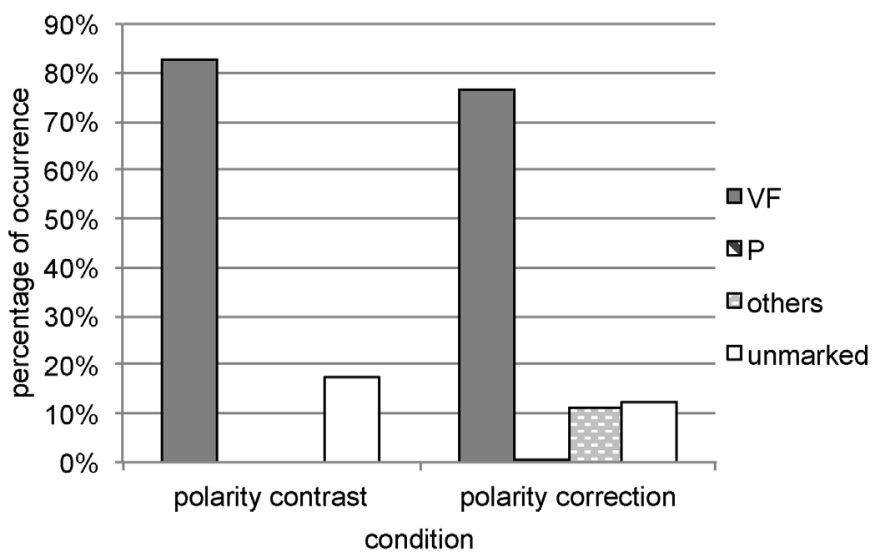

Fig. 6. Averaged distribution of Verum focus (VF), affirmative particles $(P)$, other realizations (others) and unmarked cases produced in polarity contrast and in polarity correction by German speakers.

$(\beta=-14.9, \mathrm{SE}=2.1, \mathrm{p}<.0001)$ and no effect of CONDITION $(\mathrm{p}=.3)$; the interaction between LANGUAGE and CONDITION approached significance $(\beta=4.35$, SE $=2.2, \mathrm{p}=.06)$.

Finally, we tested whether condition affects the degree of prominence also in German Verum focus. Unlike Dutch wel, Verum focus was always realized with a high-falling nuclear accent on the finite verb (i.e., $\mathrm{H}^{*} \mathrm{~L}-$, according to GToBI), independent of condition. Following Ladd and Morton (1997) and Rietveld and Gussenhoven (1985), the prominence of an accented word is related to the height of the accentual peak. In what follows, we measured the pitch range of the falling accent on the finite verbs in semitones (cf. Nolan, 2003). Results of a linear mixed effects regression model (Baayen, 2008) with SEMITONE DIFFERENCE as dependent variable, CONDITION as predictor variable (polarity contrast, polarity correction), and SPEAKER and ITEM as cross-random factors (allowing for individual adjustements of the intercept for speakers and items, cf. Cunnings, 2012; Barr et al., 2013) showed that the pitch range was significantly smaller in polarity contrast than in polarity correction (polarity contrast: on average 3.1 semitones; polarity correction: on average 5.3 semitones; $\beta=1.85, \mathrm{SE}=0.39, \mathrm{p}<.0001$ ). Thus, our analysis suggests that Verum focus is marked more prominently in polarity correction than in polarity contrast.

\section{Discussion}

The primary aim of our study was to investigate which linguistic devices (intonation or affirmative particles) speakers of German and Dutch, two closely related languages, use to signal a polarity contrast and a polarity correction and whether polarity correction is marked with more prosodic prominence than polarity contrast. Despite the similarities between these languages regarding lexicon, syntax, and focus-to-accent rules, the linguistic marking of polarity contrast and polarity correction turned out to be very different: In German, speakers generally produced Verum focus (a high-falling pitch accent on the finite verb) in the two contexts and they never produced a sentence-internal affirmative particle (like schon or wohl). They did, however, sometimes use a separate affirmative particle (doch) that preceded the Verum focus utterance. The use of the particle doch together with a Verum focus utterance only occurred in the polarity correction cases. This particle was not integrated with the rest of the utterance (neither intonationally nor syntactically) and was always followed by a Verum focus utterance. Therefore, it never carried the polarity correction function by itself. Hence, it appears that our dialogue studies confirm the tendency found in monologues (Dimroth et al., 2010): German speakers prefer to mark polarity by producing Verum focus. Future experimental studies will have to determine the specific meaning contribution of the affirmative particles doch, schon and wohl in German.

Dutch speakers, on the other hand, mostly used the accented affirmative particle wel to signal polarity contrast and correction and hardly accented the finite verb. Even when Dutch speakers did not use the particle wel they refrained from assigning a nuclear pitch accent to the finite verb (and rather accented the internal argument of the utterance, as in a noncontrastive utterance). In this respect, Dutch differs in a remarkable way from German. There is no ready syntactic or phonological explanation for this cross-linguistic difference. The question remains what Dutch speakers do when they are 'forced' not to use particles. Pilot reading data containing polarity contrast utterances without particles show that Dutch speakers do not produce Verum focus in these instances either. It hence appears that Verum focus is not the preferred option in these polarity contrast and polarity correction cases, a finding which goes in line with previous observations on 
a
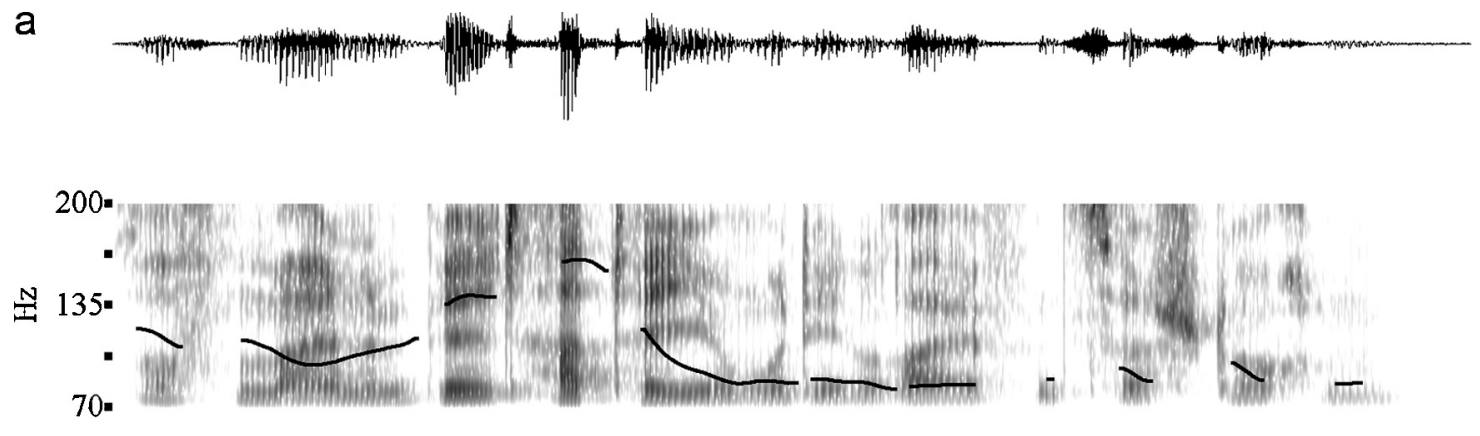

\begin{tabular}{|c|c|c|c|c|}
\hline Auf meinem Bild & hat & der Junge & den Reifen & zerstochen \\
\hline In my picture & has & the boy & the tyre & punched \\
\hline \multicolumn{5}{|c|}{ In my picture the boy punched the tyre } \\
\hline $\mathrm{L}^{*}+\mathrm{H}_{1}^{+}(\mathrm{H}-)$ & $\mathrm{H}^{*} \mathrm{~L}-$
\end{tabular}

b
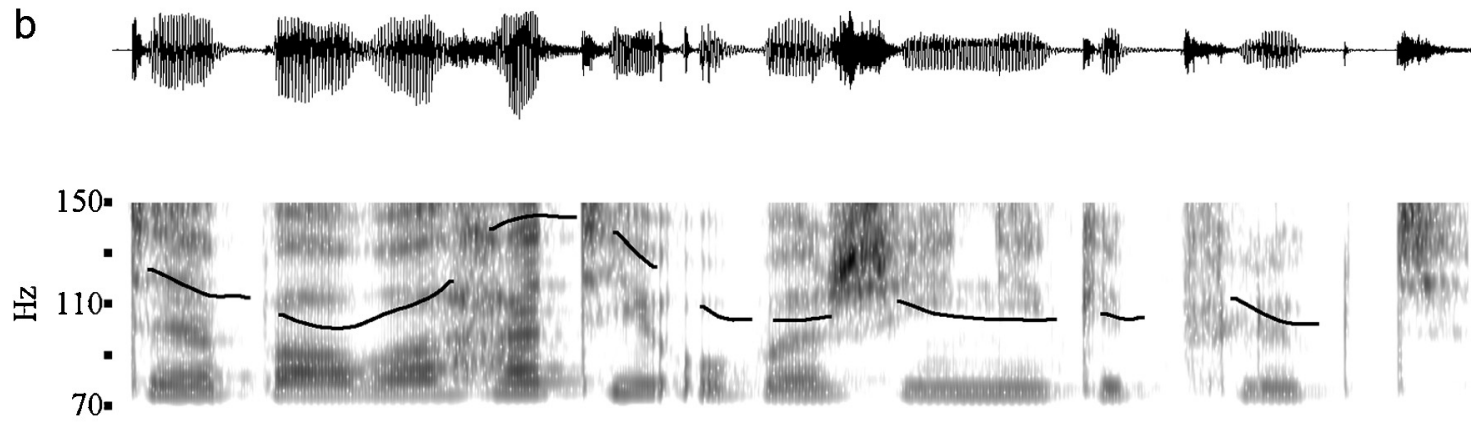

\begin{tabular}{|c|c|c|c|}
\hline Der Bauer & hat & die Aubergine & gepflueckt \\
\hline The farmer & has & the eggplant & picked \\
\hline \multicolumn{4}{|c|}{ The farmer picked the eggplant } \\
\hline $\mathrm{L}^{*}$ & $\mathrm{H}^{*} \mathrm{~L}-$ &
\end{tabular}

Fig. 7. ( $a$ and b) Example pitch tracks of polarity contrast utterance (upper panel, male speaker) and polarity correction utterance (lower panel, male speaker), both realized with a nuclear pitch accent on the finite auxiliary (hat, "has"). The GToBI annotations are shown in the last tier.

this phenomenon (cf. Gussenhoven, 1983). However, Verum focus is produced in second language acquisition (Italian). Turco et al. (submitted for publication), for instance, tested what native speakers of Dutch and German do to mark polarity contrast when the second language neither uses Verum focus nor affirmative particles. The authors found that both German and Dutch speakers produce intonation patterns that are very similar to German Verum focus when learning Roman Italian. Whereas German learners of Roman Italian can be argued to transfer their L1 intonation contours onto their L2 Italian, this interpretation is not possible for Dutch learners. After all, they employ a strategy that differs from both their L1 and Italian L2. Strikingly, their pattern is in line with the classification of Germanic languages as more assertionoriented than Romance languages (Dimroth et al., 2010). The data from Dutch and German learners of Italian hence appear to reflect the common underlying trait between German and Dutch.

These empirical differences between German and Dutch speakers might be taken to suggest that the Dutch particle wel and the German Verum focus are functionally equivalent in signalling polarity contrast and correction. This is in line with earlier suggestions (Sudhoff, 2012) and findings (Dimroth et al., 2010). It is possible that the functional equivalence of intonation and particles is dependent on the kind of particles (modal, affirmative, or focus particles) under consideration 
(Schubiger, 1965 for modal particles). Nonetheless, we believe that the functional equivalence of Verum focus and the affirmative particle wel does not necessarily imply that both devices operate on the same level: Accenting the finite verb and thus the element that carries the assertive relation between the utterance's comment and its topic should not be treated on a par with cases in which the expression of polarity (i.e., negation or affirmation) is focussed. Sentences always have a (negative or positive) polarity. While negation has to be expressed in some way, affirmation seems to be the unmarked default in most languages. Affirmation may receive an independent lexical marker (e.g., the particle wel in Dutch) when it is contrasted with negation. In addition to the contrastive lexical marker of affirmation, there is also an expression of assertion - the finite verb. The sentence thus contains a polarity operator and an assertion operator. This is different from Verum focus, in which the polarity contrast is marked by highlighting the assertion operator while affirmation is unmarked. This view seems to be shared by Blühdorn (2012) who compares the German particles ja, doch, wohl, and schon to Verum focus and maintains that even if under some circumstances both means can produce indistinguishable readings, they still operate on different levels of meaning. Furthermore, Verum focus, but not affirmative particles, can occur in negated sentences (e.g., German: Das Kind HAT nicht geweint vs. e.g., Dutch: *Het kind heeft wel niet gehuild "the child DID not cry") which suggests that the assertion operator takes effect on a level above polarity. More specifically, we argue that Verum focus operates on the level of the assertion whereas wel operates on the level of polarity (cf. discussion in Blühdorn, 2012 for affirmative particles). ${ }^{9}$

Surprisingly, we also observed that in polarity corrections, Dutch speakers used less particles than in polarity contrast. We have no explanation for the fact that an effect of condition was found for Dutch speakers but not for German speakers (compare Fig. 2 with Fig. 6). More investigations are needed to test whether this effect of condition is reliable and can be replicated.

Apart from the differences across languages, we found a striking similarity regarding the marking of polarity contrast vs. polarity correction: In both languages, the polarity correction was marked more prominently than the polarity contrast. For instance, in Dutch polarity correction the particle wel was realized more often as a fall (i.e., $H^{*} L L \%$ ), which sounds more prominent than a downstepped fall $\left(! \mathrm{H}^{*} \mathrm{~L} L \%\right)$ that was typically used in the polarity contrast condition. This difference in prominence in the particle appears to support Hogeweg's (2009) claim that an increased prominence of wel points to different degrees in the expliciteness of a context denial. In our view, it can also be argued that the difference in prominence of the particle is a secondary effect of the (prominence of the) topic marking prior to the comment. In polarity contrast, wel is preceded by a prominent contrastive topic accent (e.g., Op mijn plaatje), while in polarity correction, the topic is non-contrastive and not very salient prosodically (Braun, 2006). If we saw a way of experimentally manipulating the degree of "undoing a context denial", we would love to investigate whether the increased prominence of marking the polarity correction (as compared to polarity contrast) is caused by the strength of switching the polarity or by the preceding information structure (presence of a contrastive vs. non-contrastive topic).

\section{Funding}

This research is part of a PhD project of the first author funded by the ANR-DFG project "LANGACROSS" (DI 808/1-2, awarded to Christine Dimroth). This research was also supported by the Max Planck Institute for Psycholinguistics (Nijmegen, The Netherlands), which gave technical support, research facilities, and student assistants who helped to collect the data.

\section{Acknowledgements}

We wish to thank Sarah Schimke, Angela James, Dejan Matić, Steve Levinson, and two anonymous reviewers for their helpful comments on an earlier version of this paper.

\footnotetext{
${ }^{9}$ See also Repp (2013) for a detailed analysis on the interactions between negation, particles and the VERUM operator.
} 


\section{Appendix}

Example pitch track of polarity correction utterance (female speaker) realized with the sentence-initial particle doch followed by a nuclear pitch accent on the finite auxiliary (hat, "has"). The GToBI annotations are shown in the last tier.
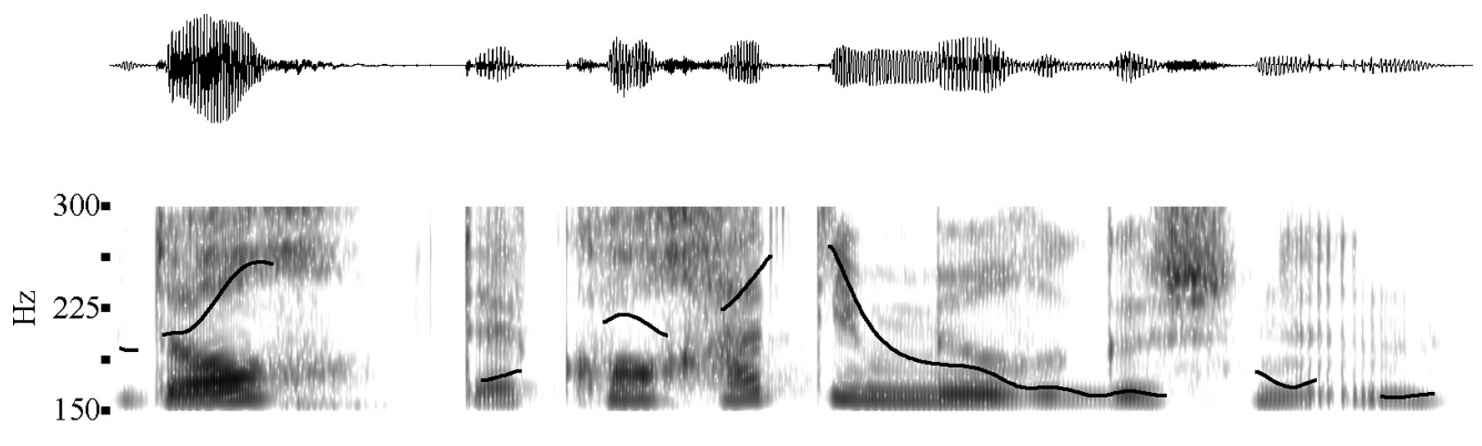

\begin{tabular}{|c|c|c|c|c|c|}
\hline Doch & $\#$ & der Koch & hat & die Moehre & geschnitten \\
\hline That's not true & & the cook & has & the carrot & cut \\
\hline \multicolumn{6}{|c|}{ That's not true \# The cook cut the carrot } \\
\hline \multicolumn{2}{|l|}{$\mathrm{L}^{*}+\mathrm{H}-\mathrm{H} \%$} & \multicolumn{3}{|c|}{$\mathrm{L}+\mathrm{H}^{*} \quad \wedge \mathrm{H}^{*} \mathrm{~L}-$} & \\
\hline
\end{tabular}

\section{References}

Baayen, R. Harald, 2008. Analyzing Linguistic Data. A Practical Introduction to Statistics using R. Cambridge University Press, Cambridge, UK.

Barr, D.J., Levy, R., Scheepers, C., Tily, H., 2013. Random-effects structure for confirmatory hypothesis testing: Keep it maximal. Journal of Memory and Language 36, 255-278.

Bates, M. Douglas, Sarkar, Deepayan, 2007. Ime4: Linear Mixed-Effects Models Using S4 Classes. R Package Version 0.99875-6 ed.

Blühdorn, Hardarik, 2012. Faktizität, Wahrheit, Erwünschtheit: Negation, Negations-Fokus und "Verum" - Fokus im Deutschen. In: Lohnstein, H., Blühdorn, H. (Eds.), Wahrheit - Fokus - Negation. Linguistische Berichte. Buske, Hamburg, pp. 137-170.

Bolinger, Dwight, 1983. Affirmation and default. Folia Linguistica 17 (1-4), 99-116.

Braun, Bettina, 2006. Phonetics and phonology of thematic contrast in German. Language and Speech 49 (4), 451-493.

Braun, Bettina, Chen, Aoju, 2010. Intonation of 'now' in resolving scope ambiguity in English and Dutch. Journal of Phonetics 38 (3), $431-444$.

Cunnings, lan, 2012. An overview of mixed-effects statistical models for second language researchers. Second Language Research 28 (3), $369-382$.

Dik, C. Simon, Hoffmann, E. Maria, de Long, R. Jan, Djiang, I. Sie, Stroomer, Harry, De Vries, Lourens, 1981. On the typology of focus phenomena. In: Hoekstra, T., van der Hulst, H., Moortgat, M. (Eds.), Perspectives on Functional Grammar. Foris, Dordrecht, pp. 41-74.

Dimroth, Christine, Andorno, Cecilia, Benazzo, Sandra, Verhagen, Josje, 2010. Given claims about new topics. How Romance and Germanic speakers link changed and maintained information in narrative discourse. Journal of Pragmatics 42 (12), 3328-3344.

Féry, Caroline, Samek-Lodovici, Vieri, 2006. Focus projection and prosodic prominence in nested foci. Language 82 (1), $131-150$.

Foolen, Ad, 2006. Polysemy patterns in contrast: the case of Dutch toch and German doch. In: Aijmer, K., Simon-Vandenbergen, A.-M. (Eds.), Pragmatic Markers in Contrast. Elsevier, Amsterdam, pp. 59-72.

Grice, Martine, Baumann, Stefan, Benzmüller, Ralf, 2005. German intonation in autosegmental-metrical phonology. In: Jun, S.-A. (Ed.), Prosodic Typology: The Phonology of Intonation and Phrasing. Oxford University Press, Oxford, pp. 55-83.

Gussenhoven, Carlos, 1983. Focus, mode and the nucleus. Journal of Linguistics 19 (2), 377-417.

Gussenhoven, Carlos, 1992. Sentence accents and argument structure. In: Roca, I.M. (Ed.), Thematic Structure. Its Role in Grammar. Foris, Berlin, pp. 79-106.

Gussenhoven, Carlos, 1999. On the limits of focus projections in English. In: Bosch, P., van der Sandt, R. (Eds.), Focus: Linguistic, Cognitive, and Computational Perspectives. Foris, Berlin, pp. 43-55.

Gussenhoven, Carlos, 2005. Transcription of Dutch intonation. In: Jun, S.-A. (Ed.), Prosody Typology: The Phonology of Intonation and Phrasing. Oxford University Press, Oxford, pp. 118-145.

Hogeweg, Lotte, 2009. The meaning and interpretation of the Dutch particle wel. Journal of Pragmatics 41 (3), 519-539.

Hogeweg, Lotte, Ramachers, Stephanie, Wottrich, Verena, 2011. Doch, toch and wel on the table. In: Nouwen, R., Elenbaas, M. (Eds.), Linguistics in the Netherlands 2011. John Benjamins, Amsterdam, pp. 52-62.

Höhle, Tilman, 1988. Vorwort und Nachwort zu Verum-Fokus. Sprache und Pragmatik, 5. Germanistisches Institut der Universitat Lund, Lund, Arbeitsberichte, pp. 1-7.

Höhle, Tilman, 1992. Über Verum-Fokus im Deutschen. In: Jacobs, J. (Ed.), Informationsstruktur und Grammatik. Westdeutscher Verlag, Opladen. (=Linguistische Berichte, Sonderhefte 4), pp. 112-141..

Horn, R. Laurence, 1985. Metalinguistic negation and pragmatic ambiguity. Language 61 (1), 121-174. 
Jaeger, T. Florian, 2008. Categorical data analysis: away from ANOVAs (transformation or not) and towards logit mixed models. Journal of Memory and Language 59 (4), 434-446.

Klein, Wolfgang, 1998. Assertion and finiteness. In: Dittmar, N., Penner, Z., Weissenborn, J. (Eds.), Issues in the Theory of Language Acquisition: Essays in Honor of Jürgen Weissenborn. Lang, Bern, pp. 225-245.

Klein, Wolfgang, 2006. On finiteness. In: Van Geenhoven, V. (Ed.), Semantics in Acquisition. Kluwer, Dordrecht, pp. $245-272$.

Klein, Wolfgang, 2008. The topic situation. In: Ahrenholz, B., Bredel, U., Klein, W., Rost-Roth, M., Skiba, R. (Eds.), Empirische Forschung und Theoriebildung. Beiträge aus Soziolinguistik, Gesprochene-Sprache- und Zweitspracherwerbsforschung; Festschrift für Norbert Dittmar zum 65. Geburtstag. Peter Lang, Frankfurt am Main, pp. 287-306.

Klein, Wolfgang, 2012. Assertion-related particles in German. In: Spalek, K., Domke, J. (Eds.), Sprachliche Variationen, Varietäten und Kontexte. Festschrift für Rainer Dietrich. Stauffenburg, Tübingen, pp. 13-38.

Ladd, D. Robert, Morton, Rachel, 1997. The perception of intonational emphasis: continuous or categorical? Journal of Phonetics 25 (3), $313-342$.

Lohnstein, Horst, 2012. Verumfokus - Satzmodus - Wahrheit. In: Lohnstein, H., Blühdorn, H. (Eds.), Wahrheit - Fokus - Negation. Linguistische Berichte. Buske, Hamburg, pp. 31-67.

Lohnstein, Horst, Blühdorn, Hardarik, 2012. Wahrheit - Fokus - Negation. Linguistische Berichte. Buske, Hamburg.

Nolan, Francis, 2003. Intonational equivalence: an experimental evaluation of pitch scales. In: The 15th International Congress of Phonetic Sciences (ICPhS), 3-9 August, Barcelona, pp. 771-774.

Pinheiro, José C., Bates, Douglas M., 2000. Mixed-Effects Models in S and S-PLUS. Springer, New York.

R Development Core Team, 2012. R: A Language and Environment for Statistical Computing. 2.15.0 ed. The R Foundation for Statistical Computing, Austria.

Repp, Sophie, 2013. Common ground management: modal particles, illocutionary negation and VERUM. In: Gutzmann, D., Gärtner, H.-M. (Eds.), Beyond Expressives - Explorations in Use-Conditional Meaning. CRISPI Series, Emerald. pp. 231-274.

Rietveld, A.M.C., Gussenhoven, Carlos, 1985. On the relation between pitch excursion size and prominence. Journal of Phonetics 13 (3), $299-308$.

Schubiger, Maria, 1965. English intonation and German modal particles: a comparative study. Phonetica 12 (2), 65-84.

Sudhoff, Stefan, 2012. Negation der Negation. Verum-Fokus und die niederländische Partikel wel. In: Lohnstein, H., Blühdorn, H. (Eds.), Wahrheit - Fokus - Negation. Linguistische Berichte. Buske, Hamburg, pp. 99-130.

Truckenbrodt, Hubert, 2012. On the prosody of German wh-questions. In: Gorka, E., Prieto, P. (Eds.), Prosody and Meaning. Walter de Gruyter, Berlin, pp. 73-118.

Turco, Giuseppina, Dimroth, Christine, Braun, Bettina, 2012. Intonational means to mark Verum focus in German and French. Language and Speech Advanced, online publication: 18 November 2012.

Turco, Giuseppina, Dimroth, Christine, Braun, Bettina. Effects of typological differences on L2 common ground management (submitted for publication).

Uhmann, Susanne, 1991. Fokusphonologie. Eine Analyse deutscher Intonationskonturen im Rahmen der nicht-linearen Phonologie (Focus Phonology. An Analysis of German Intonation Patterns Within Non-Linear Phonology). Niemeyer, Tübingen.

Umbach, Carla, 2004. On the notion of contrast in information structure and discourse structure. Journal of Semantics 21 (2), $155-175$.

Watters, John Robert, 1979. Focus in Aghem: a study of its formal correlates and typology. In: Hyman, M.L. (Ed.), Aghem Grammatical Structure (SCOPiL 7). USC Department of Linguistics Publications, Los Angeles, pp. 137-197.

Westheide, Henning, 1985. Eine kontrastive Analyse der Partikeln dt. wohl und nl. wel. Zeitschrift für germanistische Linguistik 13 (2), $186-202$.

Giuseppina Turco received her MA in Linguistics from the University of Federico II (Naples, Italy) and the University of Paris VIII. She is currently finishing her PhD at the Max Planck Institute for Psycholinguistics in Nijmegen, the Netherlands.

Bettina Braun received her PhD in Phonetics/Phonology from Saarland University in 2004. After a postdoc in the Phonetics Laboratory at Oxford University and the Comprehension Group at the Max-Planck-Insititute for Psycholinguistics in Nijmegen, she became a professor for General Linguistics at the University of Konstanz, Germany, in 2009.

Christine Dimroth received her PhD in 1998 at the Free University of Berlin. She was a researcher in the Language Acquisition Group at the MaxPlanck-Insititute for Psycholinguistics in Nijmegen, and took a full professorship for German linguistics at the University of Osnabrück, Germany in 2010. 